\title{
Burnout prevalence and associated factors in medical students in integrated modular curriculum: A cross-sectional study
}

\author{
Khurram Irshad', Ifra Ashraf ${ }^{2}$, Fahad Azam³, Abida Shaheen ${ }^{4}$
}

\begin{abstract}
Objectives: The present study aimed to explore the prevalence of burnout syndrome and to find the association of burnout symptoms with sociodemographic factors in medical students.

Methods: A cross-sectional study was conducted between September 2019 to January 2021 at Shifa College of Medicine, Islamabad. A total of 284 medical students from the first year to the fifth year participated in this cross-sectional study. After taking informed consent, students were asked to record responses on the Burnout Clinical Subtype Questionnaire BCSQ-12. In addition, a structured questionnaire was developed to obtain information about the sociodemographic status.

Results: Prevalence of burnout was observed among day scholars, females, and students having a relatively sedentary lifestyle. Low family income showed a significant association of burnout in medical students $(p=0.025)$. A significant association was found in the mean scores of neglect subtype of burnout with low family household income $(p=0.010)$. The mean scores of the overload subtype of burnout and daily duration of sleep also showed a significant association $(p=0.039)$.

Conclusion: The prevalence of burnout was associated with low household income and sleep deprivation. Gender, academic year and physical activity did not have a significant association with burnout syndrome. The high prevalence of burnout syndrome necessitates appropriate interventions to identify and reduce the prevalence of burnout in medical students.
\end{abstract}

KEYWORDS: Prevalence, Burnout, Stress, Medical education.

doi: https://doi.org/10.12669/pjms.38.4.5052

How to cite this:

Irshad K, Ashraf I, Azam F, Shaheen A. Burnout prevalence and associated factors in medical students in integrated modular curriculum: A cross-sectional study. Pak J Med Sci. 2022;38(4):801-806. doi: https://doi.org/10.12669/pjms.38.4.5052

This is an Open Access article distributed under the terms of the Creative Commons Attribution License (http://creativecommons.org/licenses/by/3.0), which permits unrestricted use, distribution, and reproduction in any medium, provided the original work is properly cited.

1. Khurram Irshad, MBBS, FCPS.

Associate Professor, Department of Physiology,

2. Ifra Ashraf, MBBS, FCPS.

Assistant Professor, Department of Physiology,

3. Fahad Azam, MBBS, M. Phil., Ph.D.

Associate Professor, Department of Pharmacology,

4. Abida Shaheen, MBBS, M.Phil., Ph.D.

Professor, Department of Pharmacology,

1-4: Shifa College of Medicine,

Shifa Tameer-e-Millat University,

Islamabad, Pakistan.

Correspondence:

Dr. Khurram Irshad

Associate Professor,

Department of Physiology,

Shifa College of Medicine,

NCBMS Tower, $\mathrm{H}-8 / 4$,

Islamabad, Pakistan.

E-mail: khurram.scm@stmu.edu.pk

* Received for Publication:

* Revision Received:

* Revision Accepted:
July 18, 2021

Decmecber 8, 2021

Decmecber 29, 2021

\section{INTRODUCTION}

Undergraduate medical education is a highly challenging and demanding path that may predispose many students to an increased risk of developing burnout and stress. Burnout syndrome may significantly affect the learning capabilities of medical students which may cause physical and psychological disturbances. ${ }^{1}$

The term burnout is described as the loss of motivation or incentive in situations when desired results are not achieved despite devotion to a goal. ${ }^{2}$ Burnout induced chronic stress leads to physical and emotional tiredness, feeling of indifference and lack of achievements in individuals working in stressful conditions. ${ }^{3}$ The professional responsibilities of healthcare professionals make them more vulnerable to stress 
and anxiety due to little room for negligence in health care delivery. The mental health of medical students is of utmost importance to manage the burden of medical education in a high-stress environment. ${ }^{4,5}$

Burnout syndrome includes two important components, namely emotional exhaustion (EE) and depersonalization (DP); emotional exhaustion (EE) is explained as emotional insensitivity along with a low perception of individual achievement. Depersonalization is described as the absence of empathy, decreased motivation and increased sense of isolation. ${ }^{6}$

Recently, burnout has been described with the help of the "Burnout Clinical Subtype Questionnaire" (BCSQ-36) which distinguishes between the three clinical variants of burnout namely the frenetic, under-challenged and wornout subtypes depending on the enthusiasm for work, lack of motivation, low appreciation and the overall working environment. ${ }^{7}$

Burnout syndrome does not only affect the learning abilities of medical students but also leads to physical, mental and social hazards like drowsiness, fatigue, eating disorders, migraine, emotional instability and drug abuse in extreme situations. ${ }^{8}$ The majority of the medical students in the UK and Australia have been found to be suffering from burnout during their medical education and revealed associated psychiatric disorders and suicidal ideation. ${ }^{9}$ Similarly, a high prevalence of burnout in students has also been reported in the public and private medical institutions of Pakistan. . $^{10,11}$

Despite the introduction of student-centred learning strategies, various factors such as communication with patients and interaction with other healthcare providers contribute to the prevalence of stress in medical students negatively affecting their physical and psychological health. ${ }^{12}$ The uncertainty about study behaviour, progress and aptitude have also been reported to be the main factors associated with stress in medical students. ${ }^{13}$

This scenario makes it important to identify the factors that cause burnout in medical students and take appropriate steps to minimize it. With this background, this study aimed to assess the prevalence of burnout syndrome and find the association of burnout symptoms with relevant sociodemographic factors among medical students in Pakistan.

\section{METHODS}

A cross-sectional study was conducted between September 2019 to January 2021 at Shifa College of Medicine, Islamabad, Pakistan after taking approval from the Institutional Review Board (IRB \# 002-492-2019). The teaching methodology comprises an active student-centred approach in an integrated modular curriculum including small group discussions (SGD), self-directed learning (SDL), problem-based learning (PBL), large group interactive sessions (LGIS) and clerkships.

A total of 284 students from the first year to the fifth year participated in the study. Students who did not provide informed consent to be a part of the study were not included. The study participants provided responses in a structured questionnaire for sociodemographic status. The sociodemographic variables included gender, marital status, academic year, residence financial status, smoking, sleeping hours and physical activity. All the participants were also asked to record responses in the Burnout Clinical Subtype Questionnaire", BCSQ-12 adapted for use with students ("Burnout Clinical Subtype Questionnaire Students Survey", or BCSQ-12-SS). ${ }^{14}$

The three clinical variants of burnout are the frenetic, under-challenged and worn-out subtypes where the "frenetic" subtype of burnout is described as stress in ambitious and overworked individuals who invest a significant proportion of time for their profession. The "under-challenged" subtype of burnout is described as stress in individuals who often perform mechanical tasks and is characterized by the feeling of lack of progression in addition to the feeling of indifference and boredom. The "worn-out" subtype of burnout is characterized by a feeling of the lack of appreciation and perception of less control over outcomes and results in a lack of interest in work responsibilities. ${ }^{7}$

Statistical Analysis: The SPSS latest Statistics version was used for data analysis. Student's t-test and ANOVA were applied for comparison between groups for quantitative variables; continuous variables were presented in mean $\pm S D$; categorical variables were presented by frequencies and percentages and were analyzed by the Chi-square and Fisher's Exact test. A p-value $<0.05$ was considered significant.

\section{RESULTS}

A total of 284 students recorded their responses. The frequencies of different sociodemographic 
factors of the study participants are summarized in Table-I. The majority of the study participants belonged to the first three years. Out of 284 students, $69 \%$ took adequate sleep of more than six hours and $67 \%$ had a relatively sedentary lifestyle and exercised less than three times a week.

The association of different demographic variables with high and low scores of burnout among medical students are shown in TableII. Participants with $>75$ th percentile for any dimension of the questionnaire were assigned high scores, while those scoring $<75$ th percentile were

Table-I: Sociodemographic data of medical students.

\begin{tabular}{|c|c|}
\hline Variables & $n(\%)$ \\
\hline \multicolumn{2}{|l|}{ Gender } \\
\hline Male & $122(43 \%)$ \\
\hline Female & $162(57 \%)$ \\
\hline \multicolumn{2}{|l|}{ Marital status } \\
\hline Single & $277(97.5 \%)$ \\
\hline Married & $7(2.5 \%)$ \\
\hline \multicolumn{2}{|l|}{ Year of study } \\
\hline First-year & $74(26.1 \%)$ \\
\hline Second-year & $93(32.7 \%)$ \\
\hline Third-year & $62(21.8 \%)$ \\
\hline Fourth-year & $17(6 \%)$ \\
\hline Final-year & $38(13.4 \%)$ \\
\hline \multicolumn{2}{|l|}{ Residence } \\
\hline Day scholar & $201(71 \%)$ \\
\hline Hostilities & $81(29 \%)$ \\
\hline \multicolumn{2}{|l|}{ Financial status } \\
\hline Low income (< Rs: 50,000 per month) & $9(3.4 \%)$ \\
\hline $\begin{array}{l}\text { Middle income (Rs: } 50,000-100,000 \\
\text { per month) }\end{array}$ & $43(16 \%)$ \\
\hline High income (> Rs: 100,000 per month) & $216(80.6 \%)$ \\
\hline \multicolumn{2}{|l|}{ Smoking } \\
\hline Smokers & $13(4.6 \%)$ \\
\hline Non smokers & $265(95.3) \%$ \\
\hline \multicolumn{2}{|l|}{ Sleeping hours } \\
\hline More than 6 hours & $193(69.4 \%)$ \\
\hline Less than 6 hours & $85(30.6 \%)$ \\
\hline \multicolumn{2}{|l|}{ Work out } \\
\hline More than 3 times/week & $92(32.7 \%)$ \\
\hline Less than 3 times/week & $189(67.2 \%)$ \\
\hline
\end{tabular}

categorized as low scorers. ${ }^{14} \mathrm{Chi}$-square analysis revealed that students with a low household income have a higher prevalence of burnout as compared to high-income groups with a high statistical significance $(p=0.020)$. The prevalence of burnout among females, day scholars, students with a relatively sedentary lifestyle and sleep deprivation was not statistically significant.

The analysis of the socio-demographic factors and mean values of total burnout scores along with mean scores of different subtypes of burnout namely lack of development, overload, and neglect are shown in Table-III. Results show a significant association between monthly income and mean scores of burnout $(p=0.025)$; a significant association was also seen with a mean

Table-II: Association of different demographic variables with high and low scores of burnouts.

\begin{tabular}{|c|c|c|c|}
\hline Variables & $\begin{array}{c}\text { High Scores } \\
>75 \\
\text { percentile }\end{array}$ & $\begin{array}{l}\text { Low scores } \\
\quad<75 \\
\text { percentile }\end{array}$ & $\begin{array}{c}p- \\
\text { value }\end{array}$ \\
\hline \multicolumn{4}{|l|}{ Gender } \\
\hline Male & $33(11.61 \%)$ & $89(31.33 \%)$ & \multirow[t]{2}{*}{.418} \\
\hline Female & $51(17.95 \%)$ & $111(39.08 \%)$ & \\
\hline \multicolumn{4}{|l|}{ Marital status } \\
\hline Single & $82(28.87 \%)$ & $195(68.66 \%)$ & \multirow[t]{2}{*}{.953} \\
\hline Married & $2(0.70 \%)$ & $5(1.76 \%)$ & \\
\hline \multicolumn{4}{|l|}{ Year of study } \\
\hline First-year & $14(4.93 \%)$ & $60(21.13 \%)$ & \multirow{5}{*}{.202} \\
\hline Second-year & $33(11.62 \%)$ & $60(21.13 \%)$ & \\
\hline Third-year & $19(6.69 \%)$ & $43(15.14 \%)$ & \\
\hline Fourth-year & $6(2.11 \%)$ & $11(3.87 \%)$ & \\
\hline Final-year & $12(2.23 \%)$ & $26(9.15 \%)$ & \\
\hline \multicolumn{4}{|l|}{ Residence } \\
\hline Day-scholar & $64(22.70 \%)$ & $137(48.58 \%)$ & \multirow{2}{*}{.191} \\
\hline Boarders & $19(6.74 \%)$ & $62(21.99 \%)$ & \\
\hline \multicolumn{4}{|l|}{ Financial status } \\
\hline Low-income & $4(1.49 \%)$ & $5(1.87 \%)$ & \multirow{3}{*}{$.020^{*}$} \\
\hline Middle-income & $20(7.46 \%)$ & $23(8.58 \%)$ & \\
\hline High-income & $57(21.27 \%)$ & $159(59.33 \%)$ & \\
\hline \multicolumn{4}{|l|}{ Work out per week } \\
\hline More than 3 times & $24(8.54 \%)$ & $68(24.20 \%)$ & \multirow[t]{2}{*}{.329} \\
\hline Less than 3 times & $60(21.35 \%)$ & $129(45.91 \%)$ & \\
\hline \multicolumn{4}{|l|}{ Smoking status } \\
\hline Smoker & $4(1.44 \%)$ & $9(3.24 \%)$ & \multirow[t]{2}{*}{.276} \\
\hline Nonsmoker & $80(28.78 \%)$ & $185(66.55 \%)$ & \\
\hline \multicolumn{4}{|l|}{ Sleeping hours } \\
\hline More than 6 hours & $55(19.78 \%)$ & $138(49.64 \%)$ & \multirow[t]{2}{*}{.456} \\
\hline Less than 6 hours & $28(10.07 \%)$ & $57(20.50 \%)$ & \\
\hline
\end{tabular}


Khurram Irshad et al.

Table-III: Analysis for mean values of total burnout score: neglect, overload and lack of development.

\begin{tabular}{|c|c|c|c|c|c|c|c|c|}
\hline \multirow{2}{*}{ Variables (n) } & \multicolumn{2}{|c|}{ Total score } & \multicolumn{2}{|c|}{ Overload } & \multicolumn{2}{|c|}{ Lack of development } & \multicolumn{2}{|c|}{ Neglect } \\
\hline & $M e a n \pm S D$ & p-value & $M e a n \pm S D$ & p-value & Mean $\pm S D$ & p-value & $M e a n \pm S D$ & p-value \\
\hline \multicolumn{9}{|l|}{ Gender } \\
\hline Male(122) & $40.96 \pm 9.50$ & .519 & $14.22 \pm 4.8$ & .484 & $14.73 \pm 4.09$ & .886 & $12.01 \pm 4.53$ & .178 \\
\hline Female(162) & $41.67 \pm 8.87$ & & $14.33 \pm 4.8$ & & $14.65 \pm 4.56$ & & $12.68 \pm 3.82$ & \\
\hline \multicolumn{9}{|l|}{ Marital status } \\
\hline Single(277) & $41.37 \pm 9.16$ & .916 & $14.32 \pm 4.8$ & .386 & $14.64 \pm 4.34$ & .248 & $12.41 \pm 4.13$ & .663 \\
\hline Married(7) & $41 \pm 8.66$ & & $21.72 \pm 6.4$ & & $16.57 \pm 4.93$ & & $11.71 \pm 4.89$ & \\
\hline \multicolumn{9}{|l|}{ Level of course } \\
\hline Year 1(74) & $40.22 \pm 8.06$ & & $14.54 \pm 4.3$ & & $14.05 \pm 3.78$ & & $11.62 \pm 4.0$ & \\
\hline Year 2(93) & $41.91 \pm 10.6$ & & $13.97 \pm 5.3$ & 572 & $14.96 \pm 4.68$ & 253 & $12.99 \pm 4.4$ & \\
\hline Year 3(62) & $42.21 \pm 7.27$ & .435 & $14.74 \pm 4.6$ & $.5 / 2$ & $14.85 \pm 3.32$ & .253 & $12.61 \pm 4.1$ & .283 \\
\hline Year 4(17) & $43.41 \pm 8.72$ & & $15.18 \pm 4.2$ & & $16.47 \pm 5.85$ & & $11.76 \pm 2.5$ & \\
\hline Year 5(38) & $39.95 \pm 9.99$ & & $13.42 \pm 5.2$ & & $14.18 \pm 5.20$ & & $12.34 \pm 4.1$ & \\
\hline \multicolumn{9}{|l|}{ Residence } \\
\hline Day-Scholar (201) & $41.66 \pm 9.01$ & .335 & $14.43 \pm 5.03$ & .324 & $14.79 \pm 4.57$ & .434 & $12.43 \pm 4.03$ & .881 \\
\hline Hostelite (81) & $40.49 \pm 9.50$ & & $13.80 \pm 4.36$ & & $14.34 \pm 3.83$ & & $12.34 \pm 4.48$ & \\
\hline \multicolumn{9}{|l|}{ Financial status } \\
\hline Low income (9) & $45.66 \pm 11.88$ & $025 *$ & $15.78 \pm 5.58$ & 288 & $15.89 \pm 14.8$ & 533 & $14 \pm 4.69$ & 010 * \\
\hline Middle income (43) & $44.16 \pm 8.04$ & $.025^{*}$ & $15.12 \pm 4.77$ & .288 & $15.16 \pm 4.20$ & .533 & $13.88 \pm 3.89$ & $.010^{*}$ \\
\hline High income (216) & $9.06 \pm .62$ & & $14.07 \pm 4.88$ & & $14.58 \pm 4.46$ & & $12.02 \pm 4.02$ & \\
\hline \multicolumn{9}{|l|}{ Workout } \\
\hline >3/week(92) & $40.80 \pm 8.63$ & .457 & $13.77 \pm 4.83$ & .221 & $14.67 \pm 4.27$ & .935 & $12.36 \pm 4.18$ & .895 \\
\hline <3/week(189) & $41.67 \pm 9.42$ & & $14.52 \pm 4.82$ & & $14.72 \pm 4.43$ & & $12.43 \pm 4.16$ & \\
\hline \multicolumn{9}{|l|}{ Smoking } \\
\hline Yes(13) & $38 \pm 12.65$ & .175 & $13.23 \pm 6.26$ & .434 & $13.15 \pm 5.73$ & .182 & $11.61 \pm 3.66$ & .499 \\
\hline $\mathrm{No}(265)$ & $41.55 \pm 9.01$ & & $14.32 \pm 4.80$ & & $14.82 \pm 4.31$ & & $12.42 \pm 4.20$ & \\
\hline \multicolumn{9}{|l|}{ Daily sleep hours } \\
\hline$\geq \operatorname{six}(193)$ & $41.08 \pm 9.12$ & .49 & $13.91 \pm 4.84$ & $.039 *$ & $14.71 \pm 4.36$ & .846 & $12.46 \pm 3.89$ & .557 \\
\hline$<\operatorname{six}(85)$ & $41.95 \pm 9.43$ & & $15.21 \pm 4.73$ & & $14.60 \pm 4.25$ & & $12.14 \pm 4.75$ & \\
\hline
\end{tabular}

score of neglect $(p=0.010)$. The mean scores of overload and daily duration of sleep showed a significant association $(p=0.039)$.

\section{DISCUSSION}

The acknowledgement of burnout as a public health problem directed scientists to find out the factors that lead to work-related diseases and to find out ways to fulfil physical, sensitive and communitybased needs arising from the onset of burnout. This scenario suggests the need for scientific studies to explore the prevalence of burnout and relevant factors in different populations with a special focus on medical undergraduate students. ${ }^{15-17}$
According to our findings, a higher prevalence of burnout was observed in females, day scholars, students with sleep deprivation and sedentary lifestyle but the association was not statistically significant. These findings are in agreement with a study conducted by Shah et al, according to which the prevalence of stress was significantly higher in females and in students who reported difficulty in sleeping; however, this study did not show a significant association of stress with low household income which is in contrast to our findings. ${ }^{11}$ Another study by Altannir et al conducted in Saudi Arabia reported that the prevalence of overall burnout was more common in female 
medical students; this study further reported that female students suffered from a low sense of personal progression, emotional exhaustion and depersonalization in comparison to male students and the prevalence of burnout reduced as the students progressed to higher classes. ${ }^{1}$ Our findings are not in agreement with these findings as our study showed a similar level of stress in all academic years. Other studies reported a higher prevalence of stress in the early years and a similar prevalence of stress in both genders. These findings are contradictory to our findings in which stress was similar in all academic years and females suffered more stress as compared to male counterparts. ${ }^{18,19}$

According to the results of our study, the prevalence of stress is significantly higher among students belonging to families with low household income; these results are in agreement with the findings reported by other researchers showing a significant association of the prevalence of stress among students belonging to families with low household income. Possible reasons for these findings could be stress induced by the inability to access books, handouts and other basic requirements. Furthermore, differences in culture, region, curriculum, diversity, teaching experience of faculty members, the level of care provided to the students and the differences in the instruments could be the reasons for stress among medical students in the reported studies. ${ }^{20,21}$

Our study showed that sleep deprivation is one of the important factors which leads to burnout in medical students which is also analyzed by different studies reporting that reduction in both sleep quality and quantity is linked with poor health outcomes leading to depression, anxiety, and feeling of self-pity. In a recently conducted study in Pakistan, emotional exhaustion was found to be the main contributor to burnout among medical students. ${ }^{22}$ Poor sleep quality may further reduce students' ability to cope with emotional challenges thus good practices and behaviours promoting good quality sleep might be beneficial to minimize stress and burnout. $22-24$

Limitations of the study: The main limitation of our study is that we could not investigate the interventions used by the medical students as coping strategies to minimize their burnout. Another limitation is the lack of focused group sessions to further explore possible reasons for burnout.

\section{CONCLUSION}

The prevalence of burnout is high in medical students with low household income and sleep deprivation. Further research is required to investigate the influence of burnout on academic performance and innovative strategies should be planned to reduce burnout in medical students.

Conflict of Interest: None.

Grant Support \& Financial Disclosures: None.

\section{REFERENCES}

1. Altannir Y, Alnajjar W, Ahmad SO, Altannir M, Yousuf F, Obeidat A, et al. Assessment of burnout in medical undergraduate students in Riyadh, Saudi Arabia. BMC Med Educ. 2019;19(1):34. doi: 10.1186/s12909-019-1468-3

2. Fontes FF. Herbert J. Freudenberger and the making of burnout as a psychopathological syndrome. Memorandum: Memory History Psychol. 2020;37. doi: 10.35699/16761669.2020.19144

3. Molero Jurado MDM, Pérez-Fuentes MDC, Gázquez Linares JJ, Barragán Martín AB. Burnout in Health Professionals According to Their Self-Esteem, Social Support and Empathy Profile. Front Psychol. 2018;9:424. doi: 10.3389/fpsyg.2018.00424

4. Farrell SM, Kadhum M, Lewis T, Singh G, Penzenstadler L, Molodynski A. Wellbeing and burnout amongst medical students in England. Int Rev Psychiatry. 2019;31(7-8):579583. doi: 10.1080/09540261.2019.1675960

5. Lee KP, Yeung N, Wong C, Yip B, Luk LHF, Wong S. Prevalence of medical students' burnout and its associated demographics and lifestyle factors in Hong Kong. PLoS One. 2020;15(7):e0235154. doi: 10.1371/journal. pone. 0235154

6. Schaufeli W, Maslach C, Marek T. Professional burnout: Recent developments in theory and research. 1st ed. Washington: Taylor and Francis; 1994;207-221.

7. Montero-Marín J, García-Campayo J. A newer and broader definition of burnout: validation of the "Burnout Clinical Subtype Questionnaire (BCSQ-36)". BMC Public Health. 2010;10:302. doi: 10.1186/1471-2458-10-302

8. Boni RADS, Paiva CE, de Oliveira MA, Lucchetti G, Fregnani JHTG, Paiva BSR. Burnout among medical students during the first years of undergraduate school: Prevalence and associated factors. PLoS One. 2018;13(3):e0191746. doi: 10.1371/journal.pone.0191746

9. Ishak W, Nikravesh R, Lederer S, Perry R, Ogunyemi D, Bernstein C. Burnout in medical students: A Systematic Review. Clin Teach. 2013;10(4):242-245. doi: 10.1111/ tct.12014

10. Asghar AA, Faiq A, Shafique S, Siddiqui F, Asghar N, Malik S, et al. Prevalence and Predictors of the Burnout Syndrome in Medical Students of Karachi, Pakistan. Cureus. 2019;11(6):e4879. doi: 10.7759/cureus.4879

11. Shah M, Hasan S, Malik S, Sreeramareddy CT. Perceived stress, sources and severity of stress among medical undergraduates in a Pakistani medical school. BMC Med Educ. 2010;10:2. doi: 10.1186/1472-6920-10-2

12. Elzubeir MA, Elzubeir KE, Magzoub ME. Stress and coping strategies among Arab medical students: towards a research agenda. Educ Health (Abingdon). 2010;23(1):355. 
13. Lewis AD, Menezes DA, McDermott HE, Hibbert LJ, Brennan SL, et al. A comparison of course-related stressors in undergraduate problem-based learning (PBL) versus non-PBL medical programmes. BMC Med Educ. 2009;9:60. doi: 10.1186/1472-6920-9-60

14. Montero-Marin J, Skapinakis P, Araya R, Gili M, GarciaCampayo J. Towards a brief definition of burnout syndrome by subtypes: development of the "Burnout Clinical Subtypes Questionnaire" (BCSQ-12). Health Qual Life Outcomes. 2011;9:74. doi: 10.1186/1477-7525-9-74

15. Safdar CA, Qayyum R. Moral Injury, Emotional Labor and Burnout: An Unbearable Burden for Health Professionals. Pak J Med Sci. 2021;37(5):1256-1258. doi: 10.12669/ pjms.37.5.4794

16. Erschens R, Keifenheim KE, Herrmann-Werner A, Loda T, Schwille-Kiuntke J, et al. Professional burnout among medical students: Systematic literature review and meta-analysis. Med Teach. 2019;41(2):172-183. doi: 10.1080/0142159X.2018.1457213

17. Hashmi AM. The challenge of Burnout in Public Medical Teachers in Pakistan: A mixed methods study. Pak J Med Sci. 2021;37(5):1268-1275. doi: 10.12669/pims.37.5.4429

18. Guthrie E, Black D, Bagalkote H, Shaw C, Campbell M, Creed F. Psychological stress and burnout in medical students: a five-year prospective longitudinal study. J R Soc Med. 1998;91(5):237-243. doi: 10.1177/014107689809100502

19. Murphy RJ, Gray SA, Sterling G, Reeves K, DuCette J. A comparative study of professional student stress. J Dent Educ. 2009;73(3):328-337.

20. Melaku L, Mossie A, Negash A. Stress among Medical Students and Its Association with Substance Use and Academic Performance. J Biomed Educ. 2015;4:1-9. doi: $10.1155 / 2015 / 149509$
21. Gushue J. Financial worries part of education for Memorial's medical students. CMAJ. 1997;157(5):559-562.

22. Abbasi M, Eraky MA, Yasmeen R, Ashfaq R. The effective coping strategies against burnout: Perceptions of Pakistani medical students. J Pak Med Assoc. 2021;71(6):1583-1587. doi:10.47391/JPMA.1292

23. Brubaker JR, Swan A, Beverly EA. A brief intervention to reduce burnout and improve sleep quality in medical students. BMC Med Educ. 2020;20:345. doi: 10.1186/ s12909-020-02263-6

24. Herawati K, Gayatri D. (2019). The correlation between sleep quality and levels of stress among students in Universitas Indonesia. Enfermeria clinica. 2010;29(Suppl-2):357-361. doi: 10.1016/j.enfcli.2019.04.044

\section{Authors Contribution:}

KI: Conceived and designed the study, collected data, drafted and reviewed the final manuscript draft.

IA: Designed the study, collected data, drafted and reviewed the final manuscript draft.

FA \& AS: Analyzed data, drafted manuscript and reviewed final manuscript draft. 